\title{
Development of serodiagnostic surface plasmon resonance imaging assay for the detection of antibodies to porcine circovirus type 2
}

\author{
Chul Park, Bum-Seok Kim, Yong-Hwan Kim¹, Ho-Seong Cho* \\ College of Veterinary Medicine and Bio-Safety Research Institute, Chonbuk National University, Jeonju 561-756, Korea \\ ${ }^{1}$ Department of Veterinary Research, Gwangju Metropolitan City Institute of Health \& Environment, Gwangju 500-210, Korea
}

(Received 16 January 2011, accepted in revised from 25 March 2011)

\section{Abstract}

\begin{abstract}
A surface plasmon resonance imaging (SPRI) assay was developed for measuring porcine circovirus type 2 (PCV2) antibody using a recombinant capsid protein as an antigen. The diagnostic potential of SPRI for detecting antibodies to the PCV2 capsid protein was compared with that of a conventional enzyme-linked immunosorbent assay (ELISA) using 70 pig serum samples taken from 6 pig farms. There was a strong positive correlation between the SPRI and ELISA $(\mathrm{n}=70, \mathrm{r}=0.911, P<0.01)$. Therefore, this recombinant capsid protein can be used as an antigen for serological studies, and the SPRI, a label-free and high-throughput method, is expected to be a valuable tool in the serodiagnosis of PCV2 infection.
\end{abstract}

Key words : Porcine circovirus type 2, Surface plasmon resonance imaging, Protein chip

\section{INTRODUCTION}

Porcine circovirus type 2 (PCV2) is the primary causative agent of several syndromes collectively known as porcine circovirus-associated disease (PCVAD) (Gillespie et al, 2009). PCVAD is a globally emerging disease that is having a huge impact on swine-producing countries and is arguably the most economically important disease affecting the global swine industry today (Gillespie et al, 2009; Opriessnig et al, 2007).

PCV2 is a small, non-enveloped, circular DNA virus that is only known to cause disease in pigs. The PCV2 has two major open reading frames (ORFs). ORF1 is essential for viral replication, while ORF2 encodes a major capsid protein (Nawagitgul et al, 2000). The ORF2 protein contains the type-specific epitopes (Mahé et al, 2000), which suggests that ORF2 contributes to the development of the disease, the vaccine potential (Liu et

\footnotetext{
*Corresponding author: Ho-Seong Cho, Tel. +82-63-270-4872,
}

Fax.+82-63-270-3780, E-mail. hscho@jbnu.ac.kr al, 2000), and type-specific diagnostic potential (Blanchard et al, 2003). Epidemiological data suggest that the virulence of the disease is strongly related to the presence of the capsid protein (Nawagitgul et al, 2000).

Several diagnostic methods for detecting PCV2 antibodies of pigs have been developed, which include neutralizing antibody test and enzyme-linked immunosorbent assay (ELISA) (Cho et al, 2006; Meerts et al, 2006). Although these methods are quite reliable, they are time- and labor-intensive protocols. Most protein arrays currently developed rely on detection technologies that employ enzymatic or fluorescent tags. In contrast, surface plasmon resonance (SPR) as a label-free technology for monitoring biomolecular interactions is a promising technique for rapid and parallel detection (Cho et al, 2006). SPR imaging (SPRI) using fast optical array detectors permits simultaneous measurements across an array of immobilized molecules. SPRI provides excellent spatial resolution at the same sensitivity as classical 
SPR. These features make SPRI a promising detection technology for biochips (Cho et al, 2006). In this study, the recombinant ORF2 protein (capsid) was used to develop a protein chip based on SPRI for measuring the antibodies of PCV2 in pig sera. The diagnostic efficacy of SPRI in determining the PCV2 infection was compared with that of conventional ELISA.

\section{MATERIALS AND METHODS}

\section{Sample collection}

A recombinant capsid protein was prepared using a prokaryotic expression system and a polyclonal antibody was prepared as described previously (Cho and Park, 2006). ELISA was used to determine the PCV2 capsid-specific antibodies in pig sera, as described previously (Cho et al, 2006). A total of 70 pig serum samples were obtained randomly from both genders (various breeds and ages) at 6 pig farms (an average of 12 serum samples per farm). The sera were prepared with $1: 100$ dilutions, and are used for ELISA and SPRI.

\section{Surface plasmon resonance imaging (SPRI) assay}

The surface modification of a gold chip for the specific binding of antigen was carried out as described elsewhere (Cho and Park, 2006). Briefly, a patterned glass slide chip with a gold film(K-Mac, Daejeon, Korea) was used to prepare the gold chip. Prior to coating with ProLinker B(Proteogen, Seoul, Korea), the gold-coated glass slides were cleaned using a freshly prepared piranha solution ( $3: 1$ mixture of concentrated $\mathrm{H}_{2} \mathrm{SO}_{4}$ and $30 \% \quad \mathrm{H}_{2} \mathrm{O}_{2}$ ). After washing with deionized water, the glass slides were dried under a $\mathrm{N}_{2}$ stream. The gold chip was prepared by soaking a clean gold-coated chip in $3 \mathrm{mM}$ ProLinker B solution for $1 \mathrm{hr}$ followed by rinsing sequentially with $\mathrm{CHCl}_{3}$, acetone, ethanol, deionized water and drying. For quantitative assays of antibodies with a minute amount of serum samples ( 1 ul per well), the antigens in PBS were spotted onto the ProLinker B coated gold chip using the ProteoChip (Proteogen, Seoul, Korea) with miniaturized micro-wells. After the spotting, the chip was incubated for $20 \mathrm{~min}$ in $80 \%$ humidity at $37^{\circ} \mathrm{C}$. The spotted chip was rinsed three times with PBST, followed by rinsing with deionized water. After adding $1 \%$ BSA in PBS for 10 min to block the chip surface, the solution containing the antibody or serum samples in a PBS buffer containing $0.1 \mathrm{mg} / \mathrm{ml}$ BSA was applied to the chip for 15 min. The chip was then dried and analyzed using the SPR imaging system(SPRi LAB, K-MAC, Daejeon, Korea). A $\mathrm{P}$ value $<0.01$ was considered significant. The Pearson's correlation coefficient (SPSS Base 12.0, SPSS, Chicago, IL) was used to determine the strength of the association between the SPR imaging and ELISA.

\section{Conventional ELISA}

The titer of PCV2-specific antibodies in pig serum was determined by ELISA as described elsewhere (Cho et al, 2006). Briefly, 96-well plates (Maxisorp; Nunc, Roskilde, Denmark) were coated with the recombinant capsid protein $(1 \mu \mathrm{g} / \mathrm{well} / 90 \mu \mathrm{l})$. The plates were then blocked with PBS containing 1\% skim milk and washed with PBS plus $0.05 \%$ Tween-20, pH 7.4 (PBST). The serum samples in $90 \mu \mathrm{l}$ of PBST (prepared with 1 : 100 dilutions) were incubated for $1 \mathrm{~h}$ at $37^{\circ} \mathrm{C}$. The plates were then emptied and washed 3 times with PBST. The bound antibody was detected with the use of HRP-conjugated goat antibody against pig IgG (Serotec, Oxford, UK) diluted $1: 500$, with incubation for $1 \mathrm{~h}$ at $37^{\circ} \mathrm{C}$, emptying, and washing 3 times with PBST. A substrate solution $(10 \mathrm{ml}$ of $0.1 \mathrm{M}$ citric acid buffer, $\mathrm{pH}$ $4.0 ; 250 \mu \mathrm{l}$ of ABTS stock solution [100 $\mathrm{mg}$ of ABTS in $4.5 \mathrm{ml}$ of deionized water (DW)]; and $50 \mu \mathrm{l}$ of $\mathrm{H}_{2} \mathrm{O}_{2}$ ) was used to detect any bound secondary antibody. The plates were then developed in the dark at room temperature for $15 \mathrm{~min}$. The absorbance at $405 \mathrm{~nm}$ was read by means of an ELISA reader (Multiskan EX; Thermo Lab Systems, Beverly, Massachusetts, USA). The results are expressed as the average \pm the standard deviation of the end-point titers. 


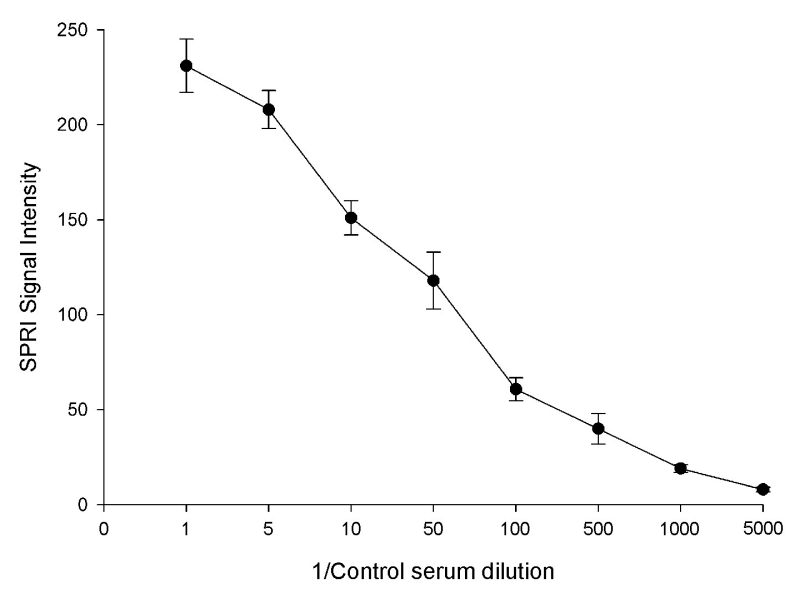

Fig. 1. The changes in surface plasmon resonance imaging signal intensity due to binding between $\mathrm{Ag}$ (capsid) immobilized Prolinker B and various dilutions of control antibody (anti-porcine circovirus type 2 ORF2 polyclonal).

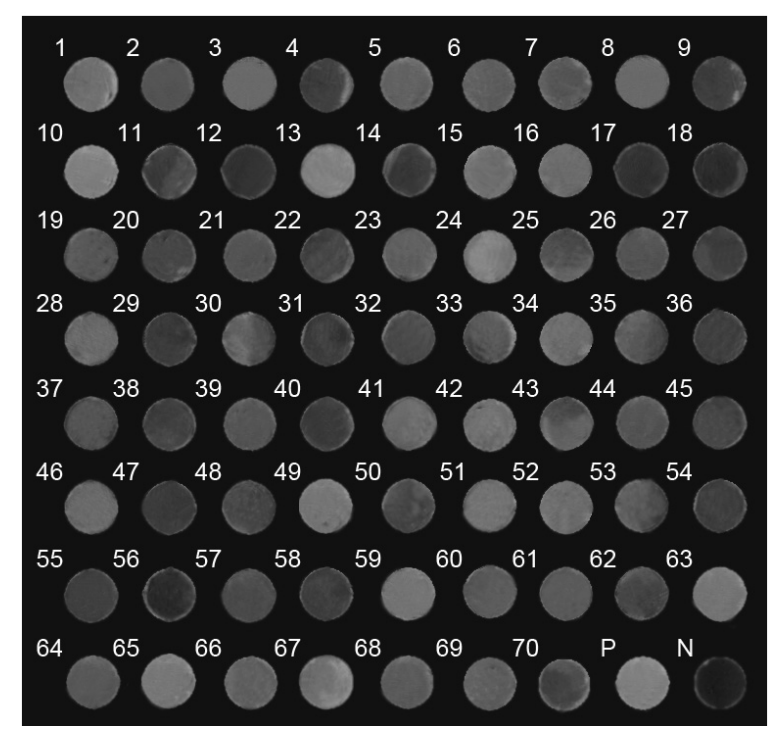

Fig. 2. Surface plasmon resonance imaging analysis of porcine circovirus type 2 antibodies (capsid as an antigen) for 70 serum samples. 1 70: serum sample number, P: positive control, $\mathrm{N}$ : negative control.

\section{RESULTS}

\section{Studies with SPRI and ELISA}

In the ELISA for detection of PCV2 specific antibodies in the pig sera, an optical density (OD) value of absorbance of $\geq 0.336$ (corresponding to 3 standard deviations above the negative controls [mean $=0.273, \mathrm{SD}=$

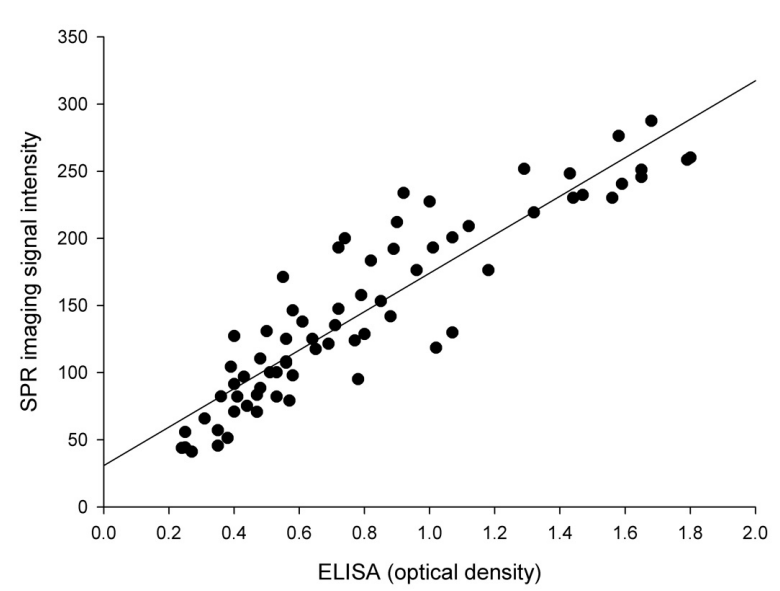

Fig. 3. Correlation between antibody optical density values of porcine circovirus type 2 in swine sera determined by ELISA and signal intensity determined by surface plasmon resonance imaging (Pearson correlation coefficient $n$ $=70, \mathrm{r}=0.911, \mathrm{P}<0.01)$.

0.021]) was considered positive. Using this cut-off value, 65 samples (92.9\%) tested positive. Fig. 1 shows the relationship between the signal intensity in the SPRI as a function of the control antibody dilution. The figure shows that the signal intensity in the SPRI increased linearly with increasing $\mathrm{Ab}$ concentration.

The detection limit of the SPRI corresponded to a 1 : 100 antibody dilution, which corresponded to a signal intensity of $55.5($ mean $=50.1, \quad S D=1.8)$. Sixty-five samples (92.9\%) also tested positive by SPRI, suggesting that a chip based on SPRI was as sensitive as ELISA (the lowest detection limit corresponded to a $1: 100$ dilution).

Fig. 2 shows the signal intensity of the 70 serum samples. Mouse anti-PCV2 capsid antibody (positive control) and "no primary antibody" (negative control) were used in the SPRI, which required only $1 \mathrm{hr}$. There was a good correlation between SPRI signal intensity and ELISA OD values for the 70 serum samples $(\mathrm{r}=0.911, P<$ 0.01) (Fig. 3).

\section{DISCUSSION}

The newly developed SPRI was used successfully to detect anti-PCV2 capsid antibodies in porcine sera in this study. This comparative study showed that although 
ELISA is quite reliable, it is time-consuming. Recently, many SPR assays have been described for detection of antibodies against pathogens such as porcine circovirus type 2 (Cho et al, 2006), classical swine fever virus (Cho and Park, 2006), Mycoplasma hyopneumoniae (Kim et al, 2006) and Mycoplasma synoviae (Oh et al, 2010). However, the SPR assay can only be applied to 2 to 4 samples simultaneously. Compared with the SPR assay, the newly developed SPRI assay with miniaturized micro-wells proved to be a rapid (assay time $1 \mathrm{hr}$ ), high-throughput, and valuable tool for the serodiagnosis of PCV2 infection.

\section{REFERENCES}

Blanchard P, Mahé D, Cariolet R, Truong C, Le Dimna M, Arnauld C, Rose N, Eveno E, Albina E, Madec F, Jestin A. 2003. An ORF2 protein-based ELISA for porcine circovirus type 2 antibodies in post-weaning multisystemic wasting syndrome. Vet Microbiol 94(1): 183-194.

Cho HS, Park NY. 2006. Serodiagnostic comparison between two methods, ELISA and surface plasmon resonance for the detection of antibodies of classical swine fever. J Vet Med Sci 68(12): 1327-1329.

Cho HS, Park SJ, Park NY. 2006. Serodiagnostic comparison of enzyme-linked immunosorbent assay and surface plasmon resonance for the detection of antibody to porcine circovirus type 2. Can J Vet Res 70(4): 263-268.

Gillespie J, Opriessnig T, Meng XJ, Pelzer K, Buechner-Maxwell V. 2009. Porcine circovirus type 2 and porcine circovi- rus-associated disease. J Vet Intern Med 23(6): 11511163.

Kim TJ, Cho HS, Park NY, Lee JI. 2006. Serodiagnostic comparison between two methods, ELISA and surface plasmon resonance for the detection of antibody titers of Mycoplasma hyopneumoniae. J Vet Med B Infect Dis Vet Public Health 53(2): 87-90.

Liu Q, Wang L, Willson P, Babiuk LA. 2000. Quantitative, competitive PCR analysis of porcine circovirus DNA in serum from pigs with postweaning multisystemic wasting syndrome. J Clin Microbiol 38(9): 3474-3477.

Mahé D, Blanchard P, Truong C, Arnauld C, Le Cann P, Cariolet R, Madec F, Albina E, Jestin A. 2000. Differential recognition of ORF2 protein from type 1 and type 2 porcine circoviruses and identification of immunorelevant epitopes. J Gen Virol 81(7): 1815-1824.

Meerts P, Misinzo G, Lefebvre D, Nielsen J, Botner A, Kristensen CS, Nauwynck HJ. 2006. Correlation between the presence of neutralizing antibodies against porcine circovirus 2 (PCV2) and protection against replication of the virus and development of PCV2-associated disease. BMC Vet Res 2: 6.

Nawagitgul P, Morozov I, Bolin SR, Harms PA, Sorden SD, Paul PS. 2000. Open reading frame 2 of porcine circovirus type 2 encodes a major capsid protein. J Gen Virol 81(9): 2281-2287.

Oh K, Lee S, Seo J, Lee D, Kim T. 2010. Rapid serodiagnosis with the use of surface plasmon resonance imaging for the detection of antibodies against major surface protein A of Mycoplasma synoviae in chickens. Can J Vet Res 74(1): 71-74.

Opriessnig T, Meng XJ, Halbur PG. 2007. Porcine circovirus type 2-associated disease: update on current terminology, clinical manifestations, pathogenesis, diagnosis, and intervention strategies. J Vet Diagn Invest 19(6): 591-615. 